\title{
Proceeding of Mulawarman Pharmaceuticals Conferences
}

Journal homepage: https://prosiding.farmasi.unmul.ac.id

\section{Skrining Fitokimia dan Uji Aktivitas Antioksidan Ekstrak Etanol Propolis Lebah Kelulut (Heterotrigona itama)}

\section{Phytochemical Screening and Antioxidant Activity Test of Kelulut Bee Propolis (Heterotrigona itama) Ethanol Extract}

\author{
Debby Putri Mutiara Yusuf1,*, Andi Tenri Kawareng², Niken Indriyanti ${ }^{3}$ \\ ${ }^{1}$ Mahasiswa Program Studi Farmasi, Fakultas Farmasi, Universitas Mulawarman, Samarinda, Indonesia \\ ${ }^{2}$ KBI Gizi, Fakultas Farmasi, Universitas Mulawarman, Samarinda, Indonesia \\ ${ }^{3}$ KBI Farmakologi, Fakultas Farmasi, Universitas Mulawarman, Samarinda, Indonesia \\ *Email korespondensi: dbbyputri03@gmail.com
}

\begin{abstract}
Abstrak
Propolis lebah kelulut (Heterotrigona itama) merupakan salah satu produk yang dihasilkan oleh lebah berupa getah sebagai pelindung sarang lebah dari predator luar dan biasa digunakan oleh masyarakat untuk pengobatan. Jenis ini juga menghasilkan propolis dengan jumlah lebih banyak dibandingkan jenis lebah lainnya, namun potensinya masih banyak belum di eksplorasi. Tujuan dari penelitian ini ialah untuk mengetahui kandungan metabolit sekunder dan aktivitas antioksidan ekstrak etanol propolis lebah kelulut asal Kutai Kartanegara. Propolis diekstraksi dengan metode maserasi menggunakan pelarut etanol $96 \%$ dan diuapkan lalu dilakukan skrining fitokimia dan uji aktivitas antioksidan dengan menggunakan metode DPPH (2,2-difenil-1-pikrilhidrazil), ekstrak etanol propolis dibuat dalam konsentrasi 25 ppm, 50 ppm, 100 ppm, 500 ppm dan 1000 ppm. Nilai rendemen ekstrak etanol propolis yang didapatkan sebesar 36\% dan uji fitokimia menunjukkan adanya senyawa flavonoid, alkaloid dan fenol serta nilai IC50 dari ekstrak etanol propolis sebesar 282,92 ppm. Hal ini menunjukkan bahwa propolis lebah kelulut dengan kandungan metabolit sekunder tersebut memiliki aktivitas antioksidan yang lemah.
\end{abstract}

Kata Kunci: $\quad$ Heterotrigona itama, Fitokimia, Antioksidan, Metode DPPH

\section{Abstract}

Kelulut bee propolis (Heterotrigona itama) is one of the products produced by bees in the form of sap as a protective bee hive from predators and is commonly used by the community for treatment. This species also produces propolis more than stinging bees, but its potential has not been explored much. 
Purpose of this study was to determine the secondary metabolites and antioxidant activity of the ethanolic extract of kelulut bee propolis from Kutai Kartanegara. Propolis was extracted by maceration method using 96\% ethanol solvent and evaporated and then carried out phytochemical screening and antioxidant activity test using the DPPH method (2,2-diphenyl-1-picrylhydrazil), ethanol extract of propolis was made in concentrations of $25 \mathrm{ppm}, 50 \mathrm{ppm}, 100 \mathrm{ppm}, 500 \mathrm{ppm}, 1000$ $\mathrm{ppm}$. The yield value of the propolis ethanol extract was $36 \%$ and the phytochemical test showed the presence of flavonoid, alkaloid and phenolic compounds and the IC50 value of the propolis extract was $282.92 \mathrm{ppm}$. This indicates that kelulut bee propolis containing these secondary metabolites has weak antioxidant activity.

Keywords: Heterotrigona itama, Phytochemical, Antioxidant, DPPH Method

DOI: https://doi.org/10.25026/mpc.v14i1.549

\section{Pendahuluan}

Lebah kelulut ialah salah satu jenis lebah penghasil madu tetapi tidak bersengat. Di Indonesia sendiri sebutan lebah kelulut sangat beragam yaitu lebah klanceng, teweul, lilin, galo-galo dan ketape [1]. Dan salah satu jenis lebah kelulut ialah Heterotrigona itama Lebah madu tanpa sengat ini memiliki perbedaan yang sangat signifikan dari bentuk tubuh dan hasil produknya dengan lebah penghasil madu lainnya. Lebah kelulut menghasilkan lebih banyak madu sekitar 5,8 $\mathrm{kg}$ dalam setahun dan rasanya cenderung asam serta penghasil propolis lebih banyak dari lebah lainnya [2].

Propolis merupakan zat yang dihasilkan oleh lebah untuk melindungi sarangnya dari berbagai ancaman, berupa getah/resin dari tanaman yang dikumpulkan oleh lebah. Propolis sendiri sudah digunakan sejak zaman purba karena memiliki banyak keistimewaan, salah satunya ialah digunakan sebagai pengobatan. Di Indonesia sendiri propolis diyakini secara empiris memiliki banyak khasiat dan relatif aman untuk digunakan dalam berbagai pengobatan tradisional. Senyawa yang terkandung dalam propolis antara lain ialah flavonoid, steroid, polifenol, vitamin, asam amino dan terpenoid yang menandakan bahwa propolis memiliki berbagai aktivitas antioksidan, antibakteri, antiinflamasi dan antivirus [3]. Kandungan propolis memiliki perbedaan tergantung pada jenis sumber getahnya, suhu, wilayah atau lingkungan sekitar budidaya.

Dari beberapa penelitian propolis yang telah ada, ditemukan beberapa faktor penentu yang mempengaruhi kualitas propolis tersebut salah satunya lokasi dan lingkungan yang memberikan peran penting dalam kualitasnya [4]. Tujuan dari penelitian ini ialah untuk mengetahui kandungan metabolit sekunder dan aktivitas antioksidan dari propolis. Pada penelitian ini peneliti melakukan penelitian dengan sampel propolis dari Desa Bhuana Jaya Kecamatan Tenggarong Seberang Kabupaten Kutai Kartanegara.

\section{Metode Penelitian}

\subsection{Alat dan Bahan}

Alat yang digunakan dalam penelitian ini ialah batang pengaduk, corong kaca, gelas kimia, hotplate, kaca objek, kertas saring, kuvet, labu ukur, pipet ukur, plastik wrap, propipet, rak tabung, rotary evaporator, spatel logam, spektrofotometer Uv-vis, tabung reaksi, timbangan analitik, toples kaca, vortex.

Bahan yang digunakan ialah Aquades, DPPH (2,2-difenil-1-pikrilhidrazil), Etanol, Etanol pro analis, $\mathrm{FeCl}_{3}$, HCL pekat, propolis lebah kelulut, reagen (Dragendroff, Mayer, Lieberman-burchard, Wagner) dan serbuk Magnesium. 


\subsection{Prosedur}

\subsubsection{Penyiapan sampel}

Sampel propolis di ambil di Desa Bhuana Jaya Kecamatan Tenggarong Seberang Kabupaten Kutai Kartanegara. Propolis lebah kelulut (Heterotrigona itama) diambil dan dipisahkan dari sarangnya. Propolis dipotong menjadi beberapa bagian kecil. Tiap potongan dikumpulkan dan dilakukan penimbangan, ditimbang beratnya sebanyak 650 gram, kemudian sampel diperoleh potongan propolis mentah yang siap untuk dilakukan proses ekstraksi.

\subsubsection{Ekstraksi sampel}

Propolis diekstraksi dengan cara merendam potongan propolis mentah menggunakan metanol $96 \%$ sampai terendam. Proses ekstraksi dengan cara perendaman dilakukan selama 2-7 hari serta dilakukan pengadukan yang selanjutnya dilakukan remaserasi hingga tuntas. Semua filtrat hasil ekstraksi dikumpulkan untuk dipekatkan menggunakan rotary evaporator dengan suhu $50^{\circ} \mathrm{C}$ dan kecepatan putaran 60 rpm sampai terbentuk ekstrak kental propolis. Ekstrak kental propolis ditimbang untuk mendapatkan nilai rendemen [5].

\subsubsection{Uji bebas etanol}

Uji bebas etanol dilakukan dengan cara menimbang 1 gram ekstrak lalu ditambahkan $\mathrm{H}_{2} \mathrm{SO}_{4}$ dan $\mathrm{CH}_{3} \mathrm{COOH}$ kemudian dipanaskan di atas hotplate. Jika hasil pemanasan, ekstrak masih tercium bau ester maka ekstrak masih mengandung etanol dan sebaliknya [6].

\subsubsection{Uji fitokimia}

Skrining fitokimia dilakukan dengan metode kualitatif berdasarkan perubahan warna dan adanya endapan menggunakan reagen spesifik untuk mengidentifikasi senyawa metabolit sekunder meliputi senyawa alkaloid, flavonoid, fenol, saponin dan steroid pada ekstrak etanol propolis [7].

\subsubsection{Uji aktivitas antioksidan}

Dibuat larutan stok DPPH 40 ppm dalam $100 \mathrm{~mL}$, sebagai blanko digunakan $2 \mathrm{~mL}$ etanol pro analis dan $2 \mathrm{~mL}$ DPPH di vortex 30 detik dan di inkubasi selama 30 menit lalu diukur absorbansinya di panjang gelombang $510 \mathrm{~nm}$ -
$520 \mathrm{~nm}$ untuk menentukan panjang gelombang maksimum. Dibuat larutan induk ekstrak etanol propolis lebah kelulut 1000 ppm selanjutnya dibuat seri konsentrasi $25 \mathrm{ppm}, 50 \mathrm{ppm}, 100$ ppm, 500 ppm dan 1000 ppm dalam $10 \mathrm{~mL}$. Diambil $2 \mathrm{~mL}$ larutan ekstrak kemudian ditambahkan larutan DPPH ke dalam tabung reaksi lalu dihomogenkan menggunakan vortex selama 30 detik.. Di inkubasi pada tempat gelap dan suhu ruang selama 30 menit. Selanjutnya diukur absorbansinya menggunakan spektrofotometer Uv-Vis pada gelombang maksimum. Dilakukan replikasi sebanyak 3 kali. Ditentukan nilai IC50 dari ekstrak dan terlebih dahulu menentukan persamaan regresi linearnya [8].

\section{Hasil dan Pembahasan}

Propolis dengan berat 650 gram setelah diekstraksi menggunakan etanol 96\% menghasilkan ekstrak sebanyak 234 gram dan nilai rendemen sebesar $36 \%$. Hasil uji bebas etanol ekstrak menunjukkan bahwa ekstrak tidak mengandung etanol karena tidak memberikan aroma ester setelah dilakukan pemanasan.

Tabel 1. Uji Organoleptis Sampel dan Ekstrak Propolis Lebah Kelulut (Heterotrigona itama)

\begin{tabular}{llll}
\hline No. & Organoleptis & Sampel & Ekstrak \\
\hline 1. & Bentuk & Padat & Cair \\
2. & Warna & Coklat tua & Coklat \\
3. & Bau & Khas madu & Khas madu \\
4. & Rasa & Hambar & Hambar \\
\hline
\end{tabular}

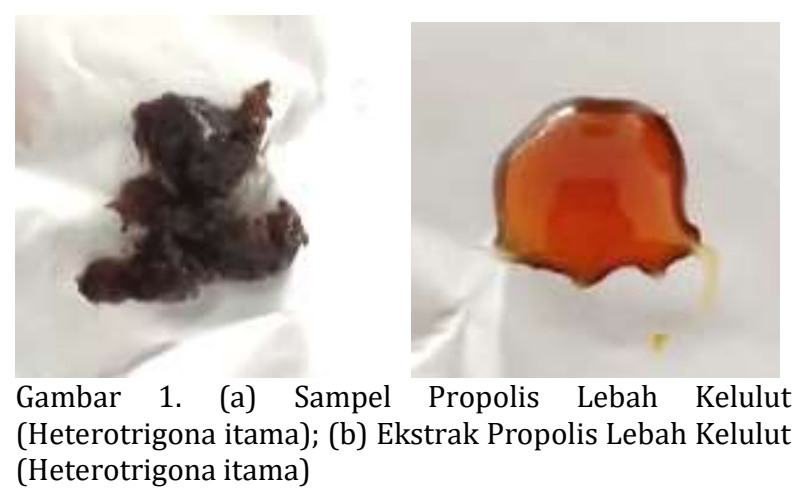

Hasil uji organoleptis sampel dan ekstrak menunjukkan hasil yang hampir sama, hanya saja terdapat perbedaan pada bentuk dimana 
pada sampel masih berbentuk padat dan setelah di ekstraksi menjadi ekstrak kental dengan bentuk cair dan terjadi perubahan warna yang awalnya coklat tua setelah di ekstraksi menjadi coklat. Untuk bau dan rasa keduanya samasama berbau khas madu dan rasa hambar.

Tabel 2. Uji Fitokimia Ekstrak Propolis Lebah Kelulut (Heterotrigona itama)

\begin{tabular}{llll} 
No. & Senyawa & Hasil uji & + /- \\
\hline 1. & Alkaloid & Adanya endapan & + \\
2. & Fenol & Berwarna hitam & + \\
3. & Flavonoid & Berwarna merah jingga & + \\
4. & Saponin & Tidak ada buih & - \\
5. & Steroid & Tidak ada perubahan warna & - \\
\hline
\end{tabular}

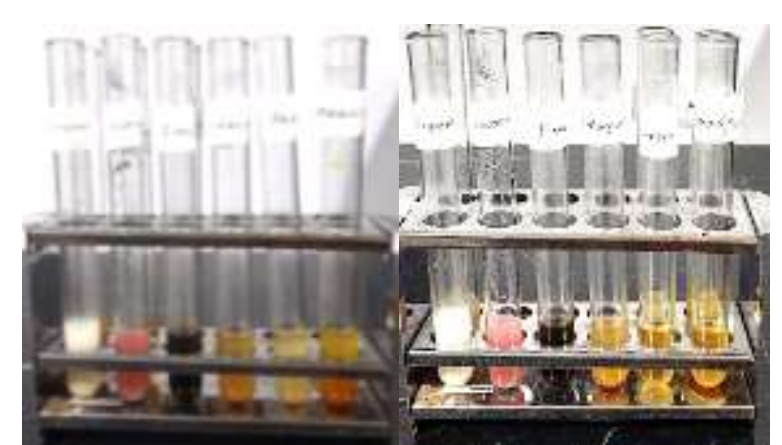

Gambar 2. Uji Fitokimia Esktrak Propolis Lebah Kelulut (Heterotrigona itama)

Hasil uji fitokimia pada ekstrak etanol propolis menghasilkan adanya senyawa alkaloid yang ditunjukkan dengan adanya endapan setelah ekstrak diberi reagen. Terdapat senyawa fenol karena setelah ekstrak diberi reagen berubah warna menjadi hitam dan terdapat senyawa flavonoid yang ditunjukkan dengan perubahan warna menjadi merah jingga setelah dipanaskan dan diberi reagen.

Tabel 3. Uji Aktivitas Antioksidan Ekstrak Propolis Lebah Kelulut (Heterotrigona itama)

\begin{tabular}{lllll}
\hline No. & $\begin{array}{l}\text { Konsentrasi } \\
\text { (ppm) }\end{array}$ & Absorbansi & \%Penghambatan & $\begin{array}{l}\text { Nilai IC } 50 \\
\text { (ppm) }\end{array}$ \\
\hline 1. & Blanko & 0,791 & 0 & \\
2. & 25 & 0,595 & $24,77 \%$ & \\
3. & 50 & 0,521 & $34,13 \%$ & 282,92 \\
4. & 100 & 0,368 & $53,47 \%$ & \\
5. & 500 & 0,138 & $82,55 \%$ & \\
6. & 1000 & 0,065 & $91,78 \%$ & \\
\hline
\end{tabular}

Pada uji aktivitas antioksidan dapat dilihat pada nilai $\mathrm{IC}_{50}$, jika semakin kecil nilai yang dihasilkan maka akan semakin besar aktivitas antioksidannya. Berdasarkan hasil uji aktivitas antioksidan pada penelitian ini didapatkan nilai $\mathrm{IC}_{50}$ ekstrak etanol propolis lebah kelulut (Hetereotrigona itama) sebesar 282,92 ppm yang menunjukkan bahwa aktivitas antioksidan ekstrak etanol propolis berada pada kategori lemah.

\section{Kesimpulan}

Berdasarkan hasil penelitian dapat disimpulkan bahwa ekstrak etanol propolis lebah kelulut dengan kandungan senyawa alkaloid, fenol dan flavonoid memiliki nilai $\mathrm{IC}_{50}$ sebesar 282,92 ppm yang menunjukkan bahwa ekstrak etanol propolis lebah kelulut dengan kandungan senyawa tersebut memiliki aktivitas antioksidan yang lemah.

\section{$5 \quad$ Kontribusi Penulis}

Debby Putri Mutiara Yusuf: Melakukan penelitian, pengumpulan data, pustaka serta menyiapkan draft manuskrip. Niken Indriyanti dan Andi Tenri Kawareng: Pengarah, pembimbing, serta penyelaras akhir manuskrip.

\section{Konflik Kepentingan}

Tidak ada konflik kepentingan dalam penelitian ini.

\section{Daftar Pustaka}

[1] Fadhilah, Rizky., Kiki Rizkika. 2015. LABA Lebah Tanpa Sengat. Trubus Swadaya, Jakarta

[2] Kementerian Lingkungan Hidup dan Kehutanan. 2016. Bahan Ajar Alih Teknologi Lebah Madu. Kuok

[3] Siregar, H. C. H., A. M. Fuah, and Y. Octaviany. 2011., Propolis Madu Multikasiat. Penebar Swadaya, Jakarta

[4] Hirmarizqi, A. A. N., Sari, E., Fembriyanto, R. K., Hidayati, N. A., \& Hertati, R. (2019). Identifikasi lebah kelulut asal Bangka dan pendataan jenis tumbuhan penghasil resin bahan baku pembuatan propolis. EKOTONIA: Jurnal Penelitian Biologi, Botani, Zoologi Dan Mikrobiologi, 4(2), 37- 42

[5] Khairunnisa, Binti., et al. 2020. Uji Fitokimia dan Antioksidan Ekstrak Etanol Propolis Lebah Kelulut (Tetragonula iridipennis) dari 
Samarinda Kalimantan Timur. Jurnal Ilmiah Manuntung, 6(1), 65-69

[6] Handayani, V., et al. 2016. Uji Aktivitas Antioksidan Ekstrak Metanol Bunga dan Daun Patikala (Etlingera elatior (Jack) R. M. Sm) Menggunakan Metode DPPH. Pharm Sci Res, ISSN 2407-2354

[7] Yuliawan, Veggy Nadia., et al. 2021. Uji Fitokimia Fraksi Etil Asetat dari Propolis Lebah
Kelulut Heterotrigona itama asal Kutai Kartanegara. Limbung Farmasi : Jurnal Ilmu Kefarmasian, Vol 2 No 2

[8] Khairunnisa, Karina., dkk., 2020., Karakteristik Fitokimia dan Aktivitas Antioksidan Ekstrak Propolis Lebah Trigona Sp. Jurnal Industri Perikanan- Vol.02 No.01 